\title{
A COBRANÇA DE ROYALTIES SOBRE A ENERGIA EÓLICA: UM ESTUDO PRELIMINAR SOBRE A PROPOSTA DE EMENDA À CONSTITUIÇÃO 97/15
}

\author{
Wesley Fernandes Araújo ${ }^{1}$ \\ Francisco Antônio Gonçalves de Carvalho ${ }^{2}$ \\ Lucas de Moura Veloso ${ }^{3}$
}

\begin{abstract}
RESUMO
O presente trabalho trata-se de uma breve análise sobre a Proposta de Emenda à Constituição (PEC) 97/15 e seus possíveis impactos. A mesma visa a cobrança de royalties sobre a energia eólica no território brasileiro. Para tanto objetivou-se analisar o texto da referida PEC e suas possíveis consequências. Metodologicamente foi realizada uma revisão bibliográfica sobre o tema e uma busca nos principais sítios eletrônicos que abordassem dados do setor. Os resultados apontaram que os principais motivos que levaram à criação desta PEC foi principalmente por se considerar que o setor impede o desenvolvimento de atividades econômicas nos locais onde os mesmos estão instalados. Contudo, foi visto que, para alguns estudiosos, por se tratar de uma energia renovável e limpa não caberia tal cobrança para o setor, além de uma série de vantagens que o mesmo traz tanto no âmbito econômico, social e ambiental. Além disso, faria com que houvesse uma preferência nas buscas por fontes de energias que são poluentes. Por outro lado, há estudos que consideram não haver uma gestão participativa das comunidades locais sobre os recursos provenientes do setor eólico, além do fato de casos em que ocorre uma imposição para implementação de parques ponderando apenas os retornos ecológicos e sua eficiência sem levar em consideração as identidades culturais e emocionais das populações com seus respectivos territórios. Contudo, é preciso avaliar pontos positivos e negativos para saber se a cobrança de royalties seja a solução para estes casos sem que gere impactos em cadeia sobre o setor eólico.
\end{abstract}

Palavras-chave: Royalties dos ventos. Setor eólico. Atividades econômicas. Desenvolvimento Econômico. Desenvolvimento ambiental e social.

\footnotetext{
${ }_{1}$ Mestre em Desenvolvimento e Meio Ambiente - Universidade Federal do Piauí (UFPI/Prodema). Especialista em Gestão Empresarial - IEMP. Graduado em Ciências Econômicas - UFPI. E-mail: fa.wesley@hotmail.com

2 Doutorando e Mestre em Desenvolvimento e Meio Ambiente - Universidade Federal do Piauí (UFPI/Prodema). Especialista em Gestão Estratégica de Mercado - IFPI. Especialista em Gestão de Pessoas - FANORTES. Especialista em Gestão Estratégica de Marketing Organizacional - FUNESO. Graduado em Administração - UFPI. E-mail: tonyogc@hotmail.com

${ }^{3}$ Especialista em Controladoria e Finanças pela Faculdade Metropolitana (Teresina-PI). Graduado em Ciências Contábeis pela Universidade Estadual do Piauí - UESPI. E-mail: mouraveloso55@gmail.com R. gest. sust. ambient., Florianópolis, v. 10, n. 2, p. 171-188, jun. 2021.
} 


\title{
THE COLLECTION OF ROYALTIES ON WIND ENERGY: A PRELIMINARY STUDY ON THE PROPOSED AMENDMENT TO THE CONSTITUTION 97/15
}

\begin{abstract}
The present work deals with a brief analysis on the Proposal of Amendment to the Constitution (PAC) 97/15 and its possible impacts. The same is aimed at collecting royalties on wind energy in Brazil. The purpose of this study was to analyze the text of the SGP and its possible consequences. Methodologically, a bibliographic review was carried out on the subject and a search in the main electronic sites that approached data of the sector. The results pointed out that the main reasons that led to the creation of this PAC were mainly because it is considered that the sector prevents the development of economic activities in the places where they are installed. However, it has been seen that, for some scholars, because it is a renewable and clean energy, it would not fit such a charge for the sector, in addition to a number of advantages that it brings both in the economic, social and environmental spheres. In addition, it would make it a preference in the search for sources of energy that are polluting. On the other hand, there are studies that consider that there is no participative management of the local communities on the resources coming from the wind sector, besides the fact of cases in which an imposition for parks implementation occurs, pondering only the ecological returns and their efficiency without taking into consideration the cultural and emotional identities of the populations with their respective territories. However, positive and negative points need to be assessed in order to know whether royalty collection is the solution to these cases without generating a chain impact on the wind sector.
\end{abstract}

Keywords: Royalties of the winds. Wind sector. Economic activities. Economic development. Environmental and social development.

\section{INTRODUÇÃO}

A Proposta de Emenda à Constituição (PEC) no 97 de 2015 dá nova redação aos artigos 20, inciso VIII e parágrafo 1ำ e 21, inciso XII, alínea "b", da Constituição Federal, tem intuito de incluir ao setor de energia eólica a cobrança de royalties assim como já é feito com o petróleo, gás natural e fontes de energia de hidrelétricas. Em poucas palavras, é como se fosse cobrar pelo espaço que suas usinas ocupam em cada região, alegando que a mesma impede o desenvolvimento de outras atividades econômicas.

Este trabalho, traz uma breve abordagem do que é proposto na PEC 97/15 assim como uma busca na literatura especializada que possa debater e explicitar se é viável ou não que tal Proposta possa ser promulgada. A importância para este estudo se deve ao fato de ser algo novo, com poucas informações e estudos já publicados, mas que merece uma atenção elevada pois a mesma, por se tratar de R. gest. sust. ambient., Florianópolis, v. 10, n. 2, p. 171-188, jun. 2021. 
algo que pode se tornar lei, precisa que as pesquisas se aprofundem mais, para que não possa haver um inequívoco caso a referida PEC seja considerada inviável por pesquisadores, empresários, e/ou ambientalistas.

Para tanto objetivou-se analisar o texto da referida PEC e suas possíveis consequências. Especificamente, buscou conhecer os debates contrários e favoráveis à aprovação da PEC 97/15, além de trazer informações mais recentes acerca do setor eólico no Brasil e os impactos por ele gerado, podendo este serem positivos ou negativos.

\section{METODOLOGIA}

A pesquisa trata-se de uma revisão da literatura a respeito dos temas abordados ao longo do trabalho e ainda trazendo, quando necessário, informações já consolidadas sobre o setor eólico e/ou de energia renovável, caracterizando-se assim também de pesquisa com dados secundários, sendo este estudo realizado entre os meses de março e abril de 2018.

Sobre a pesquisa bibliográfica, Severino (2010, p. 122) afirma que "é aquela que se realiza a partir do registro disponível, decorrente de pesquisas anteriores, em documentos impressos, como livros, artigos, teses etc. Utiliza-se de dados ou categorias teóricas já por outros pesquisadores e devidamente registrados”. Segundo Mattar (1996, p. 134), dados secundários são os "que já foram coletados, tabulados, ordenados e, às vezes, até analisados e que estão catalogados à disposição dos interessados."

\section{BREVE ABORDAGEM SOBRE PROPOSTA DE EMENDA À CONSTITUIÇÃO $97 / 15$}

Este tópico apresenta a Proposta de Emenda à Constituição 97/15 no qual pode fazer com que o Brasil seja o primeiro país a cobrar royalties da geração de energia advinda dos ventos, isto é, da energia eólica. De autoria do Deputado federal Heráclito Fortes (DEM-PI), a PEC já teve sua admissibilidade aprovada pela Comissão de Constituição e Justiça e de Cidadania - CCJ (BRASIL, 2017).

Para melhor entendimento, é preciso primeiramente definir o que é a cobrança de royalties. Conforme a Confederação Nacional de Municípios - CNM (2010, p. 7)

R. gest. sust. ambient., Florianópolis, v. 10, n. 2, p. 171-188, jun. 2021. 
"são uma das formas mais antigas de pagamento de direitos e propriedade." Além disso define como "uma indenização ao proprietário e que não se aplica a qualquer atividade econômica, mas apenas àquelas que se baseiam na extração de recursos finitos na natureza". Em outras palavras, "é a extração desse tipo de recurso natural e não os seus possíveis impactos no ambiente e na economia que geram direito a royalties".

A PEC 97/15 tem por objetivo alterar os artigos 20 e 21 da Constituição Federal de 1988, que passaria a vigorar a seguinte redação (as alterações propostas estão em destaque):

Art. 20. São bens da União:

$[\ldots]$

VIII - os potenciais de energia hidráulica e de energia eólica;

[...]

$\S 1$ ㅌ É assegurada, nos termos da lei, aos Estados, ao Distrito Federal e aos Municípios, bem como a órgãos da administração direta da União, participação no resultado da exploração de petróleo ou gás natural, de recursos hídricos e eólicos para fins de geração de energia elétrica e de outros recursos minerais no respectivo território, plataforma continental, mar territorial ou zona econômica exclusiva, ou compensação financeira por essa exploração.

[...]

Art. 21. Compete à União:

$[\ldots]$

XII - explorar, diretamente ou mediante autorização, concessão ou permissão:

b) os serviços e instalações de energia elétrica e o aproveitamento energético dos cursos de água e dos ventos, em articulação com os Estados onde se situam os potenciais hidroenergéticos e eólicos (BRASIL, 2015, grifo nosso).

O autor do projeto justifica o pedido de cobrança alegando que a exploração da energia eólica "gera significativas alterações nas áreas próximas às fazendas destinadas a essa atividade, de modo a limitar a realização de outras atividades econômicas". Dentre estas atividades que são limitadas, segundo o Deputado, está o turismo:

O turismo, por exemplo, grande fonte de renda do litoral do Nordeste, onde se localiza o maior potencial eólico do Brasil, sofre danos irreparáveis, tanto pelas restrições físicas impostas pelos parques de geração como pela deterioração de extraordinárias paisagens naturais. Essa situação provoca a redução dos empregos e da renda, além de causar impactos adversos nas contas públicas dos Estados e Municípios situados nas regiões afetadas (BRASIL, 2015).

O relator do projeto na CCJ da Câmara, deputado Tadeu Alencar (PSB-PE), em seu voto favorável à PEC, destaca ainda que:

R. gest. sust. ambient., Florianópolis, v. 10, n. 2, p. 171-188, jun. 2021. 
[...] as limitações e restrições impostas pela exploração de energia eólica afetam todo o povo brasileiro, tornando necessário que os responsáveis por tais atividades compensem os Estados, o Distrito Federal, os Municípios e a União, o que deve ocorrer através de justa participação no resultado econômico auferido, tal como ocorre com a exploração de petróleo ou gás natural e de recursos hídricos para fins de geração de energia elétrica (BRASIL, 2017).

Em seu voto, o relator da proposta ainda reconhece que a produção de energia eólica deve ser incentivada, por ser uma fonte de energia que independe de combustíveis fósseis. Contudo, ao mesmo tempo, o mesmo afirma não existir "razão para que a este tipo de atividade seja dado tratamento diferente do que a Constituição Federal", alegando que mesmo sendo uma fonte de energia limpa "a energia eólica tem algum custo, que tem sido suportado apenas pelos entes da federação em que é produzida, sem qualquer forma de compensação." (BRASIL, 2017).

$O$ relator justifica ainda que a compensação financeira se vincula aos problemas que a mesma gera, e não por causa da exploração em si. Para tanto, o mesmo traz à tona exemplos de problemas ambientais, sociais e econômicos especialmente para os municípios onde se situam as minas e as represas, podendo citar aqui: "remoção da cobertura vegetal do solo, poluição, inundação de extensas áreas, comprometimento da paisagem", além disso expõe que "inviabilizam o desenvolvimento de atividades produtivas na superfície, privando Estados e Municípios das vantagens delas decorrentes." (BRASIL, 2017).

\subsection{Principais discussões já existentes sobre a PEC 97/15}

Por se tratar de uma proposta de alteração constitucional bastante recente, há uma certa dificuldade em se encontrar na literatura especializada trabalhos que abordem o tema, sendo que os principais já existentes estão voltados para os estudos e as análises de cobranças de royalties do petróleo e do gás natural, justamente por já estarem garantidos na Carta Magna. Contudo, apesar de ser atual, e tendo ganhado força após aprovação na CCJ no final de 2017, já é possível encontrar pessoas e entidades de discutam sobre tema.

Roque Antônio Carrazza, parecerista e professor de Direito Tributário na PUCSão Paulo, conforme cita Soares (2018), "vê com ressalvas a cobrança de royalties sobre a atividade. Entretanto, considera legítimos os argumentos do deputado

R. gest. sust. ambient., Florianópolis, v. 10, n. 2, p. 171-188, jun. 2021. 
Heráclito Fortes e acredita que o Congresso poderá instituir tributos específicos para o setor."

Tratar o vento como patrimônio nacional, tal como o minério, não me parece apropriado. Porém, o proponente tem razão ao mencionar, no projeto, os impactos dos parques eólicos sobre o turismo em regiões onde a atividade é de grande importância, como o Nordeste, avalia. Assim como já é feito na mineração, por meio da CFEM [Compensação Financeira pela Exploração de Recursos], poderia se pensar em outras formas de taxação (CARRAZA, S/D apud SOARES, 2018).

Trigueiro (2018), de forma bem resumida, explica que a PEC além de ignorar o fato de que a cobrança eventual será totalmente repassada para o consumidor (por meio de oneração junto à tarifa de energia), a mesma "desconsidera os recolhimentos usuais desse setor, como PIS/Pasep [...] e ISS [...], além da remuneração direta dos pequenos proprietários rurais que autorizam a instalação dos aerogeradores em suas terras".

A presidente executiva da Associação Brasileira de Energia Eólica (ABEEÓLICA), Élbia Gannoum, conforme Soares (2018), considera "absurda" a cobrança de royalties sobre a exploração de um recurso não finito, como o vento, e ressalta que a oneração deve desacelerar o desenvolvimento de uma fonte energética limpa no país. "O conceito de royalties não se aplica aqui, porque o vento não é um recurso finito e tampouco causa impacto irreversível na propriedade. Pelo contrário, os parques eólicos incentivam outras atividades, já que levam energia elétrica para regiões onde não havia, [....]". Além disso, é afirmado ainda que "a ocupação de uma área reservada para a produção de energia eólica é de apenas $3 \% "$.

A ABEEÓLICA elaborou um breve documento com fatos, que segundo a Associação, provam que a PEC dos royalties dos ventos trará prejuízos do ponto de vista social, econômico e ambiental. A seguir, trazemos um pequeno resumo do que foi exposto no referido documento.

Primeiramente é afirmado que uma cobrança adicional sobre o setor de energia eólica, que já paga todos os impostos, taxa e tributos que são exigidos por lei "acarretará em um custo adicional e o novo valor será repassado para a tarifa nos leilões e, consequentemente, para o preço que chega no consumidor". Além disso, em épocas que o Nordeste passa por longos períodos de estiagem, o setor eólico está evitando o uso das térmicas (que costumam ser mais caras e prejudiciais ao meio

R. gest. sust. ambient., Florianópolis, v. 10, n. 2, p. 171-188, jun. 2021. 
ambiente). Por este motivo, "os royalties vão aumentar a tarifa de energia e ainda podem beneficiar expansão de fontes poluentes" (ABEEÓLICA, 2017b).

Outro fator levantado é a questão da geração de emprego e renda principalmente nas regiões onde estão instaladas suas usinas, pois "a energia eólica, além da arrecadação de impostos, leva empregos para regiões afastadas, instalação de fábricas, capacitação técnica especializada e promove a fixação do homem no campo" e com a implantação dos royalties tais regiões só teriam a perder. Além disso, "os royalties podem significar uma séria desaceleração na cadeia produtiva da energia eólica", isso porque houve nos últimos anos um forte investimento de empresas que construíram uma cadeia produtiva nacional com bastante tecnologia e eficiência, sendo que "estão instalados no Brasil, produzindo e contratando aqui. [...] Pelo menos $80 \%$ dos componentes de uma torre eólica são feitos no Brasil, [...]. Só em 2016, foram gerados 30 mil postos de trabalho na cadeia eólica” (ABEEÓLICA, 2017b).

$\mathrm{Na}$ questão ambiental os royalties poderão reduzir "o potencial da energia eólica de ajudar o Brasil a cumprir o acordo do clima", por questões ambientais, [...] a eólica surge como a opção chave para expandir o papel das renováveis na matriz elétrica. De baixíssimo impacto e de rápida implantação, com zero emissão de $\mathrm{CO}_{2}$ [...] a eólica é destaque no cumprimento do Acordo do Clima firmado em Paris. Além disso, é um grande contrassenso que haja mais uma cobrança para setor no exato momento em que muitos outros países (que estão preocupados e comprometidos com o futuro de nosso planeta) têm buscado "incentivar o crescimento saudável das energias limpas, como é o caso das eólicas" (ABEEÓLICA, 2017b).

A Política energética nacional é outro fator que é diretamente atingido caso a cobrança de royalties seja realmente aplicada, já que contraria o princípio de utilizar fontes alternativas de energia, mediante o aproveitamento econômico dos insumos disponíveis e das tecnologias aplicáveis, além de estar em desacordo com o preceito da Política de mitigar as emissões de gases causadores do efeito estufa. Vale destacar ainda que "os parques eólicos não prejudicam a fauna e a flora e não provocam impactos ambientais nas regiões onde são instalados", já que seus processos de instalação passam por rigorosos estudos e licenciamentos de Órgãos Estaduais e Nacionais de Meio Ambiente. (ABEEÓLICA, 2017b).

R. gest. sust. ambient., Florianópolis, v. 10, n. 2, p. 171-188, jun. 2021. 
Klein (2018) traz à tona as palavras do presidente do Sindicato das Empresas de Energia Eólica do Rio Grande do Sul (Sindieólica-RS), Guilherme Sari. Para o referido presidente:

\begin{abstract}
Um novo encargo impactaria o preço da energia, encarecendo o produto para o consumidor final. O presidente do Sindieólica-RS recorda que a produção da energia eólica permite a manutenção de outras atividades produtivas, como a criação de gado ou a prática da agricultura no mesmo espaço em que estão situados os aerogeradores. [...] os complexos eólicos já dão retorno em impostos como o ICMS e ISS, além da geração de emprego que proporcionam. Sari adianta que se o investimento no segmento eólico no Brasil começar a ficar oneroso por causa de taxas, os empreendedores poderão começar a migrar para outros países da América do Sul como Argentina, Chile ou Peru (KLEIN, 2018).
\end{abstract}

Por parte da população em geral, uma pesquisa realizada pelo DataSenado, em parceria com a Universidade de Columbia, aponta para que a incidência dos royalties na energia renovável não prospere, já que $85 \%$ dos entrevistados concordaram total ou parcialmente que o Brasil invista mais nas fontes eólica e solar. Essa maioria é formada por 55\% que concordaram totalmente e $30 \%$ parcialmente com a aplicação de mais recursos nessa área (DATASENADO, 2015).

De forma resumida, vimos que há poucas discussões relacionadas ao tema, e quem defende a implantação da PEC 97/15 é pesquisador de direito tributário, enquanto quem é contrário, são os próprios empresários que trabalham diretamente com o setor ou pesquisadores ambientais. Como visto no tópico referente a PEC em estudo a maior preocupação está ligada com a limitação que o setor eólico pode dar ao turismo de áreas litorâneas por causa de seu avanço em áreas de paisagens naturais. Como já visto antes, estas ocupações chegam a apenas ser entre 3\% e 5\%, segundo informações da ABEEÓLICA, mas ainda colocamos na seção 4 a seguir informações acerca da energia eólica no País e seus principais impactos.

\title{
4 NÚMEROS RECENTES DA ENERGIA EÓLICA NO BRASIL E SEUS IMPACTOS
}

O processo de produção eólica é uma das principais fontes de energia sustentável, limpa e renovável. Esse processo vem ganhando destaque como fonte alternativa de produção de energia elétrica, cuja produção em escala comercial teve início há pouco mais de 30 anos, mas sua tecnologia vem avançando rapidamente (OLIVEIRA; SANTOS, 2008). Isso foi resultado de significativos investimentos em

R. gest. sust. ambient., Florianópolis, v. 10, n. 2, p. 171-188, jun. 2021. 
Pesquisa \& Desenvolvimento e uma política de criação de mercado através de políticas de incentivos em vários países, especialmente na Alemanha, Dinamarca, Estados Unidos, e mais recentemente na Espanha (JANUZZI, 2003).

A produção de energia eólica no Brasil possui subsídios do Governo Federal através do Programa de Incentivo às Fontes Alternativas de Energia Elétrica (PROINFA). Freitas e Dathein (2013) observam que os custos relacionados a instalações de fontes renováveis se dão por duas formas: a primeira diz respeito aos custos relativos à aquisição de novas tecnologias e equipamentos, e o segundo, são os relativos à aprendizagem, que normalmente são expressivos quando se adota a mudança. Os altos preços do estágio inicial e desenvolvimento da energia eólica lhe conferiam baixa competitividade, nesse viés mostrou-se de extrema importância os subsídios do governo para a adoção dessa energia na matriz energética do país.

Outro ponto de destaque trazido pela implantação de usinas de produção de energia eólica no Brasil é a contribuição para a redução na emissão de gás carbônico na atmosfera. Segundo a ABEEÓLICA (2017a), o total de emissões de $\mathrm{CO}_{2}$ evitadas no ano de 2016 chegaram a 17,81 milhões de toneladas, equivalente à quantidade produzida por praticamente toda a frota da cidade de São Paulo.

Conforme Saidur, et al. (2011) e Vries, et al. (2007) a energia eólica é limpa, compatível para a geração elétrica em grande escala, e em termos tecnológicos é amigável ao meio ambiente, além de proporcionar reduzida poluição ambiental e consumo de água e não produz $\mathrm{CO}_{2}$ e de ter o risco reduzido de insegurança de fornecimento. A instalação do projeto é rápida, quando se compara a outras fontes energéticas, já que as turbinas eólicas são produzidas em escala industrial e podem ser rapidamente instaladas e conectadas à rede elétrica (CEARÁ, 2001).

Jabber (2013) ainda agrega à estas informações afirmando que a energia eólica não requer combustível, não cria gases tóxicos e não produz lixo radioativo. Dincer (2000) considera que a grande solução para os problemas ambientais mundiais reside nas tecnologias de energia renovável, o que seria a base para o desenvolvimento sustentável global, em especial quando se consideram os problemas associados às emissões de poluentes.

Os novos investimentos em geração de energia eólica resultam na geração de empregos nas cidades contempladas. Nesse sentido surgiu o termo Green Jobs (empregos verdes), que diz respeito aos empregos que reduzem o impacto ambiental

R. gest. sust. ambient., Florianópolis, v. 10, n. 2, p. 171-188, jun. 2021. 
de empresas e de setores econômicos, de forma que contribuam para a preservação ou restauração da qualidade ambiental (PNUMA, 2008). Para Simas e Pacca (2013), a discussão sobre a geração de empregos pelas energias renováveis ganhou força no início da década de 2000 , resultado das incertezas sobre a efetividade econômica e seus efeitos sobre a economia. A produção de energia eólica no Brasil gerou, no ano de 2012, 15 mil empregos diretos (MELO, 2013). O total de empregos criados na produção de eletricidade através da energia dos ventos é cerca de cem vezes maior do que a gerada por um reator nuclear, considerando quantidades idênticas de eletricidade (LUCON; GOLDEMBERG, 2009).

Uma informação atual do setor, são os dados consolidados do boletim InfoMercado mensal da Câmara de Comercialização de Energia Elétrica, que revelou um crescimento de $26,5 \%$ da geração de energia eólica em operação comercial no Sistema Interligado Nacional - SIN, em 2017, na comparação com 2016. No Período foi possível observar que o setor abasteceu $10 \%$ do País em agosto e $11 \%$ em setembro de 2017, passando pela primeira vez aos dois dígitos na matriz nacional num mês. (CCEE, 2018b). Além disso, o setor chegou a abastecer mais de $60 \%$ do Nordeste em vários momentos, na época que é conhecida como "safra dos ventos", que ocorre no período de junho a novembro (ABEEÓLICA, 2018).

Números recentes do setor eólico mostram que ela está presente em mais de 80 países sendo que a Índia, a China e a América Latina são considerados como mercados em crescimento. Os primeiros lugares do mundo em capacidade de energia instalada são a China (114.609 MW), os Estado Unidos (65.879 MW), a Alemanha (39.165 MW), a Espanha (22.987 MW), a Índia (22.465 MW) e o Reino Unido (12.440 MW) (GWEC, 2014). No final de 2014 a energia eólica era capaz de abastecer o equivalente a $39 \%$ da demanda por eletricidade da Dinamarca, $20 \%$ da Irlanda, Portugal e Espanha e 4,9\% dos Estados Unidos (GWEC, 2014).

No Brasil, o setor está em franca expansão: segundo relatório do Ministério de Minas e Energia, a produção desse segmento no País cresceu $33 \%$ somente no período entre 2015 e 2016. Já em 2017, o Brasil registrou capacidade de gerar 13 GW de energia por meio de seus 518 parques eólicos já instalados, sendo que encontrava até o período ainda outros 4,87 GW de capacidade em construção, segundo dados da Associação Brasileira de Energia Eólica. Os $13 \mathrm{GW}$ de capacidade instalada de energia eólica ainda significam que o setor já gerou mais de 195 mil postos de trabalho

R. gest. sust. ambient., Florianópolis, v. 10, n. 2, p. 171-188, jun. 2021. 
desde seu início, com grande concentração nos últimos oito anos (ABEEÓLICA, 2018). A Tabela 1 a seguir apresenta como estão divididos os parques e potência instalada por Estado, no qual podemos observar uma participação maior dos estados pertencentes ao Nordeste Brasileiro.

Tabela 1 - Distribuição da capacidade instalada e potência do setor eólico por Estado em 2017

\begin{tabular}{|c|c|c|}
\hline UF & Potência (MW) & № de Parques \\
\hline Rio Grande do Norte & $3.722,45$ & 137 \\
\hline Bahia & $2.594,54$ & 100 \\
\hline Ceará & $1.950,46$ & 75 \\
\hline Rio Grande do Sul & $1.831,87$ & 80 \\
\hline Piauí & $1.443,10$ & 52 \\
\hline Pernambuco & 781,99 & 34 \\
\hline Santa Catarina & 238,50 & 14 \\
\hline Maranhão & 220,80 & 8 \\
\hline Paraíba & 157,20 & 15 \\
\hline Sergipe & 34,50 & 1 \\
\hline Rio de Janeiro & 28,05 & 1 \\
\hline Paraná & 2,50 & $\mathbf{5 1 8}$ \\
\hline Total & $\mathbf{1 3 . 0 0 5 , 9 5}$ & \\
\hline
\end{tabular}

Fonte: Câmara de Comercialização de Energia Elétrica - CCEE (2018a).

Simas e Pacca (2013), em trabalho apoiado pela ABEEÓLICA, acreditam que a matriz energética eólica pode contribuir para o desenvolvimento sustentável do país, além de ser considerada mais intensiva em empregos que as tecnologias tradicionais a combustíveis fósseis, uma vez que podem gerar, até 2020, 330 mil empregos por ano no país, sendo que empregos diretos corresponderiam a $70 \%$ desse montante, na cadeia de operação, construção e fabricação. Outra vantagem no caso brasileiro é que pode suprir as necessidades energéticas de populações isoladas, pois no caso de haver turbinas pequenas, estas são capazes de atender às demandas específicas com velocidades menores de vento (ANEEL, 2005).

Por outro lado, Gorayeb e Brannstrom (2016), ao realizar um estudo sobre Gestão Participativa dos Parques Eólicos no Nordeste do Brasil, mais especificamente no Estado do Ceará, destacam alguns problemas que estão diretamente ligados à logística de fornecimento ou a instalação das redes de transmissão do setor eólica, além de considerem haver uma falta de retorno para as populações locais onde estão instalados os parques. Segundo os autores:

A indústria que abastece o mercado com peças e equipamentos e as empresas que constroem e gerenciam os parques eólicos no Brasil relatam diversos problemas relacionados à infraestrutura do país como estradas ruins, a falta de linhas de transmissão interligando as usinas eólicas às subestações da Companhia Hidrelétrica do São Francisco (CHESF) e da

R. gest. sust. ambient., Florianópolis, v. 10, n. 2, p. 171-188, jun. 2021. 
Companhia Elétrica do Ceará (COELCE), falta de educação tecnológica da população, escassez de fábricas especializadas nas peças e compostos das turbinas e veículos apropriados para transportar grandes cargas, como as pás das hélices, por exemplo. Não existe uma política de estado consistente, de caráter nacional ou regional, que tenha como meta contemplar a sociedade com os ganhos da indústria da energia eólica, trazendo divisas para a região onde os parques são instalados, qualificando a mão-de-obra e investindo fortemente em fixação e avanço tecnológico (GORAYEB; BRANNSTROM, 2016, p. 104).

Gorayeb e Brannstrom (2016) destacam, a partir de sua análise, que há certos problemas que cercam as políticas de implementação dos parques eólicos no Nordeste, com destaque às questões relacionadas à falta de regularização fundiária dos povos tradicionais e à fragilidade dos sistemas jurídicos em relação à garantia dos direitos dos habitantes dessas comunidades.

Enquanto Simas e Pacca (2013) em estudo da realidade brasileira, e documento do governo do estado do Ceará (CEARÁ, 2001), que focaliza a situação cearense, declararem que os parques de energia eólica podem coexistir com diversas atividades econômicas como pecuária e agricultura e que os proprietários da terra não são desalojados, podendo permanecerem em suas moradias ainda aumentar a produtividade rural, a partir do investimento dos recursos adquiridos através do pagamento de aluguéis, Lima (2009) destaca que isto ocorre apenas onde há segurança da posse da terra e estabilidade jurídica da propriedade, o que não ocorre com as comunidades tradicionais do litoral do Ceará, por exemplo, que vivem como "posseiros de boa-fé" em seus territórios e não possuem certezas legais de permanência.

De acordo com Pasqualetti (2011), os conflitos sociais correlacionados à energia renovável resultariam da "imposição" da energia eólica sem compensação ou mitigação, quando os investidores e os gestores valorizam mais os assuntos técnicos, como eficiência e qualidade de vento, acima de considerações sociais, como os vínculos produtivos e emocionais das pessoas com o território.

Molina e Tudela (2008) consideram interessante, no nível de planejamento territorial, a elaboração de zoneamento para propor áreas que atendam às expectativas ambientais e sociais e que sejam mais adequadas à implantação de parques eólicos, construído em parceria com todas as esferas da sociedade, levandose em consideração o suporte físico-territorial-conservacionista e os aspectos históricos, culturais e econômicos das comunidades.

R. gest. sust. ambient., Florianópolis, v. 10, n. 2, p. 171-188, jun. 2021. 
Gorayeb e Brannstrom (2016) finalizam seus estudos, com base em seu estudo de caso e em guias de boas práticas para a implementação de parques eólicos de diversos países e citam algumas propostas para a adequação da implementação dos parques de energia eólica, especificamente no Ceará:

(I) segurança legal da posse da terra pelas comunidades tradicionais; (II) pagamento de royalties e aluguéis às associações comunitárias; (III) abatimento das contas de energia dos moradores locais; (IV) criação de programas permanentes de educação e promoção de boas práticas voltadas à comunidade local; (V) construção de dispositivos legais que normatizem a implementação da energia eólica a nível estadual e municipal, a partir da elaboração de leis e planos municipais; (VI) elaboração de estudos de impacto ambiental que tenham como premissa a conscientização pública, informação ampla e estratégias de comunicação acerca dos benefícios e possíveis danos ao ambiente natural, social e à saúde humana; e (VII) construção de um zoneamento estadual que identifique níveis de compatibilidade das regiões do estado com a implantação de parques eólicos, com ampla participação social (GORAYEB; BRANNSTROM, 2016, p. 111).

Gorayeb e Brannstrom (2016) reconhecem ainda que há uma ausência de pesquisas sobre vários aspectos relacionadas à energia renovável no Brasil. Os autores destacam que as pesquisas da área geográfica deveriam descrever e quantificar a aceitação ou rejeição social às usinas eólicas para simplificar as comparações com outros casos brasileiros e com a bibliografa internacional, para:

(I) entender a dimensão fundiária e estabelecer um diálogo com pesquisas
sobre o impacto territorial da energia renovável; (II) analisar a cadeia entre o
investidor e os vários intermediários, como as elites locais, para desmistificar
as relações financeiras e sociais; (III) entender as estratégias políticas dos
grupos de oposição para facilitar comparações com outros casos, nacionais
e globais, de oposição à energia renovável e obras de infraestrutura; (IV)
pesquisar meios para melhorar a capacidade de negociação entre as
comunidades e os investidores na energia eólica (GORAYEB;
BRANNSTROM, 2016, p. 111).

Desta maneira, nota-se que mesmo com a rápida ascensão do setor eólico no Brasil, há uma série de benefícios econômicos, sociais e ambientais que por si só dispensam a necessidade e que, para alguns especialistas, uma cobrança de royalties fariam com que tais vantagens fossem mitigadas, o que poderia fazer o que País andasse na contramão das exigências e acordos já firmados no mundo todo sobre o clima e produção de energia limpa.

Por outro lado, alguns estudiosos destacam uma ausência de retorno às comunidades locais onde são implantados os parques, estando isto relacionado ao fato destas não participarem diretamente das negociações para que se beneficiem diretamente com os lucros do mercado de geração de energia eólica, além de em

R. gest. sust. ambient., Florianópolis, v. 10, n. 2, p. 171-188, jun. 2021. 
muitas situações em que há uma certa imposição que leva em consideração apenas os resultados eficientes trazidos pelo vento se sobrepondo as questões de identidade das populações com seus referidos territórios. Isso faz com que ocorra conflitos sociais o que exige a implantação de políticas públicas relacionadas a uma gestão participativa dos recursos renováveis gerados por este tipo de energia renovável.

\section{CONSIDERAÇÕES FINAIS}

Ao longo deste trabalho foi observado os principais motivos que levaram a criação da PEC 97/15 para que possam ser cobrados royalties no setor de energia eólica, principalmente por impedir o desenvolvimento de atividades econômicas nos locais onde so mesmos estão instalados. Contudo, foi visto que por se tratar de uma energia renovável e limpa não caberia tal cobrança para o setor, além de uma série de vantagens que o mesmo traz tanto no âmbito econômico, ou social, ou como no ambiental, tais como a baixa emissão de $\mathrm{CO}_{2}$, geração de emprego e renda, valorização da cadeia produtiva dentro do território nacional, e redução do uso de termelétricas em período de estiagem.

De forma resumida, para alguns autores e especialistas do setor, todos estes benefícios por si só já se tornam suficientes para que o setor de energia eólica possa custear seus "impactos de localização", mas vale lembrar que o mesmo já tem suas atividades tributadas que são exigidas por leis, como PIS/Pasep e ISS. Mais uma cobrança significaria perda de competitividade em leilões e mais um repasse no preço final dos consumidores. Além disso, faria com que houvesse uma preferência nas buscas por fontes de energias que são poluentes.

É necessário ainda considerar casos em que outros estudiosos destacam não haver uma gestão participativa sobre os recursos proporcionados pelo setor, sendo esses mais precisamente econômicos e sociais no qual há um isolamento político em que não dão voz nem atribui legitimidade às demandas locais, exigindo a implantação de políticas públicas capazes de proporcionar melhores retornos às comunidade locais e tradicionais.

É preciso ponderar todos os pontos, positivos e negativos, para saber se a cobrança de royalties é algo que será a solução para estes problemas. Como visto outras soluções também são propostas e é claro que o trabalho aqui apresentado é um estudo breve, mesmo porque as informações encontradas ainda são poucas e R. gest. sust. ambient., Florianópolis, v. 10, n. 2, p. 171-188, jun. 2021. 
recentes, trazendo principalmente a perspectiva de pesquisadores das áreas ambientais ou profissionais do setor eólico, mas é de suma importância que haja um aprofundamento das pesquisas por outros setores interessados, visto que é algo que se entra em vigor na Constituição Federal poderá trazer consequências sérias e talvez até irreversíveis para o País, se não for feita sem considerar todos os aspectos envolvidos e cada realidade em que os parques estão instalados nas suas respectivas áreas geográficas.

\section{REFERÊNCIAS}

ABEEÓLICA (Associação Brasileira De Energia Eólica). Boletim Anual de Geração de Energia Eólica - 2016. São Paulo, (2017a). Disponível em:

https://goo.gl/TfrwN5. Acesso: 10 mar. 2018.

ABEEÓLICA (Associação Brasileira De Energia Eólica). Brasil chega a 13 GW de capacidade instalada de energia eólica. 21 de fevereiro de 2018, São Paulo, (2018). Disponível em: https://goo.gl/mKYeZR. Acesso: 10 mar. 2018.

ABEEÓLICA (Associação Brasileira De Energia Eólica). Dez fatos que provam que a PEC dos royalties dos ventos será prejudicial do ponto de vista econômico, social e ambiental. (2017b). Disponível em: https://goo.gl/ZaiZzf. Acesso: 10 mar. 2018.

ANEEL (Agência Nacional de Energia Elétrica). Atlas de energia eólica do Brasil. Brasília: ANEEL, 2005. 243p.

BRASIL. Câmara dos Deputados. PEC 97/2015, 2015. Disponível em: https://goo.gl/wsccdN. Acesso: 15 mar. 2018.

BRASIL. Comissão de Constituição e Justiça - CCJ. Proposta de Emenda à Constituição № 97 de 2015 dá nova redação aos artigos 20, VIII e § 1, e 21, XII, “b”, da Constituição Federal, 2017. Disponível em: https://goo.gl/jPfzkL. Acesso: 18 mar. 2018.

BRASIL. Senado Federal. Energia no Brasil: alternativas e cenários futuros. Secretaria de Transparência. Coordenação de Controle Social. Serviço de Pesquisa DataSenado. 2015. Disponível em: https://goo.gl/JYbGcf. Acesso: 15 fev. 2018.

BUTTERBY, R.; FERREIRA K. C. A energia eólica como alternativa sustentável para o centro-oeste. Conjuntura Econômica Goiana. Instituto Mauro Borges, n. 10, junho de 2009. Disponível em: https://goo.gl/FMRQsg. Acesso: 23 set. 2018.

CEARÁ. Estado do Ceará. Atlas do potencial eólico. Fortaleza: Secretaria de Infraestrutura, 2001, 32p.

R. gest. sust. ambient., Florianópolis, v. 10, n. 2, p. 171-188, jun. 2021. 
CCEE (Câmara de Comercialização de Energia Elétrica). InfoMercado mensal: geração eólica cresce 26,5\% em 2017. Brasil, 20 de fevereiro de 2018. (2018a) Disponível em: https://goo.gl/2PqkFd. Acesso: 15 fev. 2018.

CCEE (Câmara de Comercialização de Energia Elétrica). Geração eólica tem aumento de $27 \%$ de janeiro a novembro de 2017. Brasil, 17 de janeiro de 2018. (2018b). Disponível em: https://goo.gl/Yv9F2H. Acesso: 22 mar. 2018.

CNM (Confederação Nacional de Municípios). Estudos Técnicos. Brasília, 2010. $48 p$.

DINCER, I. Renewable energy and sustainable development: a crucial review.

Renewable and Sustainable Energy Reviews, v. 4, p. 157 - 175, 2000.

FREITAS, G. S.; DATHEIN, R. As energias renováveis no Brasil: uma avaliação acerca das implicações para o desenvolvimento socioeconômico e ambiental. Revista Nexos Econômicos, Salvador, v. 7, n.1, jan. /jun., 2013.

GORAYEB, A.; BRANNSTROM, C. Caminhos Para uma Gestão Participativa dos Recursos Energéticos de Matriz Renovável (Parques Eólicos) no Nordeste do Brasil. Mercator, Fortaleza, v. 15, n. 1, p. 101-115, jan./mar., 2016.

GWEC. Global wind report: annual market update 2014. Belgium, 2015, 80p. JABBER, S. Environmental Impacts of Wind Energy. Journal of Clean Energy Technologies, v. 1, n. 3, p. $251-254,2013$.

JANUZZI, G. M. Uma avaliação sobre as atividades recentes de P\&D em energia renovável no Brasil e Reflexões para o futuro. Energy Discussion Paper. v. 03. n. 2, 2003

KLEIN, J. “Avança projeto de royalties sobre a energia eólica” Jornal do Comércio - Porto Alegre/RS, 07 de janeiro de 2018. Disponível em: https://goo.gl/ia2mPH. Acesso: 25 jun. 2018.

LUCON, O.; GOLDEMBERG, J. Crise financeira, energia e sustentabilidade no Brasil. Estudos Avançados, v. 23, n. 65, p. 121-130. 2009.

MATTAR, F. N. Pesquisa de Marketing. São Paulo: Atlas, 1996.

MELO, E. Fonte eólica de energia: aspectos de inserção, tecnologia e competitividade. Estudos Avançados, São Paulo, v. 27, n.77, p. 125-142, 2013.

MOLINA, R. J.; TUDELA, S. M. L. Elección de criterios y valoración de impactos ambientales para la implantación de energía eólica. Papeles de Geografía, v. 47-48, p. 171-183, 2008.

OLIVEIRA. T. F. F.; SANTOS, H. I. Uso da energia eólica como alternativa para mitigar o agravamento do efeito estufa. Disponível em: https://goo.gl/ojuZJs. Goiânia, 2008. Acesso: 15 jun. 2018.

R. gest. sust. ambient., Florianópolis, v. 10, n. 2, p. 171-188, jun. 2021. 
PASQUALLETI, M. J. Social barriers to renewable energy landscapes.

Geographical Review, v. 101, n. 2, p. 201-223, 2011.

PNUMA (Programa das Nações Unidas para o Meio Ambiente). Empregos Verdes: trabalho decente em um mundo sustentável e com baixas emissões de carbono. 2008. Disponível em: https://goo.gl/w3FH6j. Acesso: 15 fev. 2018.

SAIDUR, R. et al. Environmental impact of wind energy. Renewable and Sustainable Energy Reviews, v. 15, p. 2423-2430, 2011.

SEVERINO, Antônio Joaquim. Metodologia do trabalho científico. 22. ed. São Paulo: Cortez, 2010.

SIMAS, M.; PACCA, S. Energia eólica, geração de empregos e desenvolvimento sustentável. Estudos Avançados, v. 27, n. 77, p. 99-116, 2013.

SOARES, J. "Royalties para energia eólica fazem sentido?" Deutsche Welle Brasil, 02 de fevereiro de 2018. Disponível em: http://p.dw.com/p/2rzTQ. Acesso: 15 mar. 2018.

TRIGUEIRO, A. "Brasil pode ser o primeiro país a cobrar royalties da energia eólica". Folha de São Paulo. SP, 07 de janeiro de 2018. Disponível em: https://goo.gl/5pLiHQ. Acesso: 25 mar. 2018.

VRIES, B. J. M. et al. Renewable energy sources: their global potential for the frsthalf of the 21st century at a global level: an integrated approach. Energy Policy, v. 35, p. 2590-2610, 2007. 


\section{APÊNDICE A - Nota explicativa sobre a atualização na tramitação da PEC 97/15}

No momento da submissão deste artigo, a PEC em estudo encontrava-se arquivada. Porém, tal arquivamento ocorreu no dia 31/01/2019, não por ter sido rejeitada em processo em sessões da Câmara, e sim em virtude dos termos do Artigo 105 do Regimento Interno da Câmara dos Deputados, tendo em vista a não reeleição do Deputado que fora o autor da referida proposta. A PEC poderia ter seu desarquivamento, caso o parlamentar fosse reeleito e fizesse requerimento nesse sentido dentro dos primeiros cento e oitenta dias da primeira sessão legislativa ordinária da legislatura subsequente, retomando a tramitação desde o estágio em que se encontrava. Entretanto, considerando a aceitação que esta PEC teve na CCJ não se pode deixar de supor que outra(s) proposta(s) com mesmo teor possa $(\mathrm{m})$ ressurgir para debate e por este motivo o referido estudo aqui realizado ainda pode ser considerado relevante para que demais pesquisadores possam se aprofundar mais acerca deste tema, realizando mais pesquisas e estudos de caso, proporcionando à sociedade em geral melhor compreensão dos possíveis impactos (positivos ou negativos) que poderiam ser gerados.

R. gest. sust. ambient., Florianópolis, v. 10, n. 2, p. 171-188, jun. 2021. 